\title{
Paulo Freire e a gestão democrática como política educacional: oposições ao neoliberalismo
}

\author{
Paulo Freire y la gestión democrática como política educativa: \\ oposiciones al neoliberalismo \\ Paulo Freire and the democratic management as educational policy: \\ oppositions to neoliberalism \\ DAIANNY MADALENA COSTA \\ http://orcid.org/0000-0001-7045-0259 \\ Universidade do Vale do Rio dos Sinos \\ Programa de Políticas e Organizações educacionais \\ Santa Catarina, SC, Brasil \\ FERNANDA PAULO \\ https://orcid.org/0000-0002-8022-9379 \\ Universidade do Oeste de Santa Catarina \\ Programa Pós-graduação em Educação \\ Santa Catarina, SC, Brasil
}

\begin{abstract}
Resumo: O conceito de gestão democrática em Paulo Freire ancora-se num projeto popular, político e pedagógico. $\mathrm{O}$ artigo, por isso, analisa sua relação com a política educacional e as tensões neoliberais, a qual perversamente demarca o arrefecimento à democracia. Por meio de pesquisa bibliográfica e análise hermenêutico-dialética, aponta-se para a necessidade de radicalizar a democracia, reinventando-a e desconstruindo o discurso e práticas autoritárias, presentes no projeto de educação neoliberal e mercadológica. É necessário, portanto, avançar em torno da compreensão sobre a participação popular dialógica.
\end{abstract}

Palavras-chave: Paulo Freire. Políticas educacionais. Gestão democrática. Neoliberalismo.

\begin{abstract}
The concept of democratic management in Paulo Freire is anchored in a popular, political, and pedagogical project. Therefore, the article analyzes its relationship with the educational policy and neoliberal tensions, which wickedly marks the cooling down to democracy. Through the bibliographic research and a bermeneutic-dialectical analysis, it is pointed out the need to radicalize democracy, reinventing it and deconstructing the discourse and authoritarian practices, present in the neoliberal and marketing education project. It is necessary, therefore, to advance around the understanding of popular dialogical participation.
\end{abstract}

Keywords: Paulo Freire. Educational policies. Democratic management. Neoliberalism. 
Resumen: El concepto de gestión democrática en Paulo Freire se ancla en un proyecto popular, político y pedagógico. El artículo, por eso, analiza su relación con la política educacional y las tensiones neoliberales, las cuales, perversamente demarcan el desmoronamiento de la democracia. Por medio de pesquisa bibliográfica y un análisis hermenéutico-dialéctico, se señala la necesidad de radicalizar la democracia, reinventándola y deconstruyendo el discurso y las prácticas autoritarias, presentes en el proyecto de educación neoliberal y mercadológica. Es necesario, por tanto, avanzar en torno de la comprensión de la participación popular dialógica.

Palabras clave: Paulo Freire. Politicas educacionales. Gestión democrática. Neoliberalismo.

\section{INTRODUÇÃO}

O presente artigo resulta de nossas reflexões acerca das seguintes questões: qual a relação das ideias de Paulo Freire para a gestão democrática como uma política educacional? Quais relações entre a gestão democrática freiriana com o Plano Nacional de Educação (PNE) e seus contrapontos em tempos neoliberais? Para refletirmos e produzirmos uma análise sobre essas problematizações, beneficiamo-nos de uma pesquisa bibliográfica a partir de autores que embasam a pedagogia crítica e, em especial, de Paulo Freire (1961, 1967, 1977, 1979a, 1979b, 1982, 1995, 2001, 2003, 2011, 2013, 2014, 2015).

O principal objetivo é identificar, no arcabouço freiriano, elementos para uma superação das ideias antidemocráticas, perversamente alardeadas e estimuladas pelo neoliberalismo. Para tanto, propomo-nos a debater, de modo crítico, o embate entre uma gestão democrática e o gerencialismo apregoado pelas lógicas do mercado. Para isso, nosso ponto de partida é a contextualização neoliberal, seguindo a presença da gestão democrática como contraponto à educação autoritária, com base em Paulo Freire. Na sequência, uma articulação entre o(s) conceito(s) de democracia em diálogo com a meta 19, do PNE (BRASIL, 2014).

Nesse sentido, nossa reflexão está dividida em quatro partes: inicialmente, de modo conciso, apresentamos o contexto neoliberal, para dar sequência à presença da concepção de gestão democrática em Paulo Freire e sua contribuição para o debate acerca das políticas educacionais. Serão apresentadas referências de Paulo Freire antes e depois da ditadura militar no Brasil (1964-1985), pois esse tema acompanhou o autor durante toda sua trajetória de educador - até sua morte. Ainda em seu último livro, "Pedagogia da autonomia: saberes necessários à prática educativa", Freire (2011) defendeu a democracia radical contra todo tipo de discriminação e autoritarismo. Na segunda seção, identificamos a relação da gestão democrática na política educacional a partir de legislações brasileira, como a Constituição Federal, que traz a "gestão democrática do ensino público" (BRASIL, 1988), e a Lei de Diretrizes e Bases da Educação Nacional (LDBEN) 
de 1996; ambas apresentam o direito à participação, na construção de uma escola democrática. O princípio da democracia na escola é parte de um processo de rompimento com as formas burocráticas, centralizadoras, impositivas e autoritárias vivenciadas em seu cotidiano. Freire (1991) assenta sua contribuição sobre a importância de uma gestão progressista, bem como da "palavração" (FREIRE, 1979a), que significa a negação do verbalismo, como forma dicotômica entre a fala e a ação (FREIRE, 2013). Pontuamos, por isso, que a gestão democrática da educação ainda tem percalços, mas continua sendo uma exigência, mesmo que assolada por constantes desafios (CURY, 2002).

$\mathrm{Na}$ terceira parte, discutimos os aspectos presentes no PNE (BRASIL, 2014), referentes à gestão democrática, sob a perspectiva analítica das aprendizagens freirianas. Freire (1979b, 2013) apresenta o princípio da dialogicidade para a construção de uma participação concreta e popular. Nesse sentido, gestão democrática, conforme os pressupostos freirianos, requer um método pedagógico de libertação, isto é, necessita de um "método de diálogo - crítico e que convide à crítica" (FREIRE, 1979b, p. 28) que realmente transforme a realidade das pessoas, da escola, da comunidade, da cidade e do mundo.

$\mathrm{Na}$ última parte, antes das considerações finais, expomos a acepção de democracia em livros e artigos de Paulo Freire, identificando sua proposta de educação no campo da pedagogia crítica. $\mathrm{O}$ educador concebe a democracia participativa como um processo político-pedagógico que deve ser experienciada através de práticas e teorias libertadoras. Por essa razão, é urgente, na proposta freiriana de educação, radicalizar a democracia, a qual caminha junto com o compromisso com a ética humanizadora.

\section{CONTEXTO NEOLIBERAL}

No cenário neoliberal, característico do século XX, a partir do final da década de 1970, a destruição das formas tradicionais de soberania dos estados (COSTA, 2020) e "das divisões do trabalho, das relações sociais, da promoção de bem-estar social, das combinações de tecnologias, dos modos de vida e de pensamento" (HARVEY, 2014, p. 13) desaguou no esfacelamento de um estágio civilizatório da sociedade pós-industrial, que entre muitas contradições, buscava, dentro das regras do capital, por meio da regulação do Estado, possibilidades de bem-estar. Isso empurrava grande parte das lutas e manifestações para superações que pudessem alargar direitos humanos, justiça e dignidade de vida para homens e mulheres. 
No entanto, a formação de um modelo neoliberalista desvia tais conquistas para um conjunto de mecanismos que serão devidamente apropriados pelo mercado e sua lógica nefasta. Diante disso, Frigotto (2000) denunciou três estratégias utilizadas: a desregulamentação (supressão das normas e leis), a descentralização e a privatização.

No campo educacional, Christian Laval compreendeu a fantástica captura da escola para esse sistema, afirmando que:

O novo modelo escolar e educativo que tende a se impor está fundamentado,
inicialmente, na sujeição mais direta da escola à razão econômica. Ele depende
de um "economismo" aparentemente simplista cujo axioma principal é que
as instituições, em geral, e as escolas, em particular, só têm sentido dentro do
serviço que elas devem prestar às empresas e à economia. O "bomem flexível" e o
"trabalhador autônomo" constituem, assim, referências do novo ideal pedagógico. (LAVAL,
2004, p. 03, grifos nossos).

Além disso, o autor evidencia três facetas imprescindíveis para a derrocada da escola pública e democrática, que são: a desinstitucionalização (quanto mais a escola responder positivamente às regras do mercado, mais fluidas se tornam sua estabilidade e sua autonomia); a desintegração (ao aceitar as normas de individualização, de que a educação deva responder aos objetivos individuais em detrimento do coletivo, da sociedade, romperá com seus ideais republicanos); e, por último, a desvalorização (a erosão da escola como locus da cultura e do conhecimento).

No panorama atual, portanto, ao agudizarem-se as marcas da lógica neoliberal, é preconizada por esse sistema uma árdua disputa com um contexto educacional democrático e progressista, o qual centra "fogo" nas concepções de sua organização. Diante disso, podemos percebê-las no conjunto das diversas reformas empreendidas, principalmente àquelas que contundentemente afirmam a meritocracia, os rankings, a instituição de vouchers - como cheques disponibilizados às famílias para que "escolham" a escola para seus filhos, as privatizações, as formações aligeiradas da docência (LAVAL, 2004) e a gestão de cunho empresarial, fortemente atrelada ao gerencialismo. Essas mudanças se alastraram fortemente para os países periféricos, por meio dos acordos e das recomendações feitas pelos organismos internacionais (Banco Mundial e Fundo Monetário Internacional, mais especialmente).

Apple (2005) enfatiza que, para além das estratégias econômicas, o neoliberalismo efetivamente desenvolve-se para modificar o modo com que homens e mulheres "sejam e estejam" no mundo. Pelo menos, tem destacadas estratégias para isso. É o que podemos verificar com os inúmeros acontecimentos sobre os comportamentos de supervalorização do consumo, do valor ao 
serviço privado, dos sentidos de desconfiança, insegurança e individualismo, do sujeito "que seja empreendedor, ousado e competitivo" (APPLE, 2005, p. 37), constantemente avaliado e vigiado, sempre colocado em xeque - se está sendo eficiente, "custe o que custar". Homens, mulheres e o próprio Estado estão submetidos à comercialização, o tempo todo.

Obviamente, tais condições acompanham uma perda em relação à democracia, porque são cada vez mais reduzidas as possibilidades para um engajamento em busca do bem comum, de valores coletivizados, de oportunidades de bem-estar mais universal. Além disso, há um permanente ataque a essas proposições. E é, portanto, essa a ideia primordial para o paradigma neoliberal: arrefecer a democracia e o Estado democrático de direito permanentemente. Por isso,

A democracia não só deve demonstrar sua capacidade para governar o sistema político e a sociedade; também deve ser um instrumento idôneo para a construção de uma sociedade melhor. A ingovernabilidade nos fala de um mal-estar profundo originado na persistência de um regime de produção intrinsecamente injusto. Sob certas condições o capitalismo desenvolvido pôde compensar politicamente as iniquidades da exploração assalariada. No entanto, na atualidade parece que isso não é mais possível - pelo menos da mesma maneira - e se assista a uma ofensiva frontal da direita nos âmbitos econômicos, "intelectuais e morais", e políticos. (BORON, 2002, p. 29).

No caso brasileiro, isso se faz bastante compreensível, pois diante da história de crueldade implementada no país entre opressores e oprimidos - desde a escravidão e que se alastra até os dias atuais - e, por isso, parece configurar-se como uma terra firme para as concepções neoliberalistas. Sendo assim, Freire (1995) propõe, em “À sombra desta mangueira”, o principal compromisso de intelectuais progressistas, ao contrário daqueles identificados com os paradigmas neoliberais: "Em lugar do fatalismo imobilista, proponho um crítico otimismo que nos engaje na luta por um saber que, a serviço dos explorados, esteja à altura do tempo atual."

As tensões colocadas e vividas no cotidiano escolar têm relação com tudo isso. Surgem do fortalecimento das lógicas neoliberalistas, mas vale lembrar que "a escola neoliberal ainda é uma tendência e não uma realidade acabada" (LAVAL, 2004, p. XIV). Do mesmo modo, assim como tal projeto não está concluído, Freire (1995) compreende que ele pretende nos obstaculizar e imobilizar. É desse movimento que o anúncio ao compromisso de educadores progressistas, que reconhecem a luta e a esperança diante da monstruosidade que nos é apresentada, ganha cada vez mais sentido e necessidade. "Reconheço a realidade. Reconheço os obstáculos, mas me recuso a acomodar-me em silêncio ou simplesmente tornar- 
me o eco macio, envergonhado ou cínico, do discurso dominante." (FREIRE, 1995, p. 43). Isso parece, portanto, justificar ainda mais a gestão democrática da educação, como veremos a seguir.

\section{RADICALIZAR A DEMOCRACIA: UMA PROPOSTA FREIRIANA}

Partimos da ideia do neoliberalismo como uma "fábrica de perversidades" (SANTOS, 2000, p. 19), marcada pelo avanço da financeirização, de um "sistema fiscal favorável às empresas, a fraqueza do direito social e dos sindicatos” (LAVAL, 2004, p. XII) e uma forte ofensiva à democracia (BORON, 2002), incluindo mudanças no que se refere ao comportamento dos sujeitos em sociedade (APPLE, 2005). Para tal modelo, é preciso destruir a democracia, porque, ao fim e ao cabo, é por meio dela que se tornará possível o recuo ao projeto desumano defendido.

O jogo nefário e cruel justificado pela elite ao longo da história brasileira é muito anterior ao que estamos concebendo por neoliberalismo, por isso, a luta pela democracia na escola, em Paulo Freire, é antecedente às suas experiências como secretário de Educação do município de São Paulo. Em sua tese (FREIRE, 2003), fica explícita a ligação entre democracia e participação e, para tanto, é importante conceber a nossa democracia em aprendizagem, necessitando a ruptura com as relações antidialógicas, mecanicistas, autoritárias e assistencialistas. No entanto, a participação em Paulo Freire é princípio da democracia. A democracia popular é apontada como processo de superação ao autoritarismo. Quanto à escola, Freire (2003) declara que ela e a própria universidade estão marcadas pela inexperiência democrática de nosso país.

No ano de 1960, em uma conferência organizada pelo Centro Regional de Pesquisas Educacionais do Recife-PE, Paulo Freire (1961, p. 100) defendeu uma escola democrática, "uma escola de trabalho, de diálogo, da participação, da 'comunicação'." Argumentou que há uma constante necessidade de experiência dialogais, afirmando que "sem a qual dificultaremos nosso aprendizado democrático" (p. 101). Mais tarde, em 1982, no "Caderno de Ensino", revista da União Estadual de Estudantes do Rio Grande do Sul, anuncia que é necessário "construir uma plataforma comum de lutas que aponte para uma nova escola, gratuita autônoma e democrática.” (FREIRE, 1982, p. 13).

Quando Paulo Freire foi secretário de Educação do município de São Paulo, em 1989, cunhou e implantou políticas educacionais com base na participação, entre elas a criação dos Conselhos Escolares, o Programa de Formação Permanente de Educadores e o Movimento de Alfabetização de Jovens e Adultos (MOVA), em parceria com os movimentos populares. Então, tivemos uma experiência significativa de gestão democrática, que se efetivava dois meses 
depois da promulgação da Constituição Federal de 1988, a qual previu a gestão democrática do ensino público, no artigo 206 (BRASIL, 1988). Isso ocorreu sete anos antes da disposição da LDBEN (BRASIL, 1996). As experiências de educação democrática do educador e sua equipe foram reconhecidas pela Sociedade Brasileira para o Progresso da Ciência, no ano de 1993, entidade que citou as obras de Freire como contributo para a construção da democracia autêntica ${ }^{1}$. Outras experiências, inspiradas em Paulo Freire, emergiram a partir daí, sendo implementadas em Porto Alegre-RS, Caxias do Sul-RS e Belo Horizonte-MG.

Recordamos que o livro "Pedagogia do oprimido" foi considerado transgressor e violento no período da ditadura civil-militar. Suas ideias foram perseguidas pelos representantes da direita, tendo em vista que os educadores de esquerda as apoiaram (GADOTTI, 1996, 2012). Nesta obra, Freire (2013, p. 83) afirma que: "falar, por exemplo, em democracia e silenciar o povo é uma farsa." O educador desaprova a cultura do silêncio presente na educação bancária e na sociedade antidemocrática. Contrário à pedagogia autoritária, apresenta o diálogo como base da democracia ao lado da participação autêntica (FREIRE, 2011, 2013).

Todavia, Paulo Freire (2003), desde sua tese defendida em 1959, apresentou críticas contra a sociedade antidemocrática e, mais tarde, contrapôsse aos ideais neoliberais, expondo seu repúdio frente "à malvadez neoliberal, ao cinismo de sua ideologia fatalista" (FREIRE, 2011, p. 10). Freire e Guimarães (2013), dialogando sobre democracia, declaram a necessidade do imperativo ético ao lado dela, principalmente diante dos ideais neoliberais.

Concernente à importância da democracia na pedagogia de Freire, no seu último livro encontramos sua contrariedade a todos os tipos de ditaduras e dos falsos discursos democráticos (FREIRE. 2011), asseverando sua defesa em favor da importância de sonharmos com outra sociedade. Sobre isso afirma que:

Um desses sonhos para que lutar, sonho possível mas cuja concretização demanda coerência, valor, tenacidade, senso de justiça, força para brigar, de todas e de todos os que a ele se entreguem, é o sonho por um mundo menos feio, em que as desigualdades diminuam, em que as discriminações de raça, de sexo, de classe sejam sinais de vergonha e não de afirmação orgulhosa ou de lamentação puramente cavilosa. No fundo, é um sonho sem cuja realização a democracia de que tanto falamos, sobretudo hoje, é uma farsa. (FREIRE, 2001, p. 25).

1 Informação retirada no texto: "Paulo Freire, patrono da Educação Brasileira". Disponível em: https://paulofreire.org/paulo-freire-patrono-da-educacao-brasileira. Acesso: 18. abr. 2021. Publicado originalmente em: http://www.eicos.psycho.ufrj.br/anexos/port_paulfr.htm. 
Com essas posturas, é legítimo afirmarmos que a gestão democrática é um tema recorrente nas obras de Paulo Freire, desde seus primeiros escritos, embora não se utilizasse do termo "gestão" nas primeiras publicações. Em uma pesquisa realizada pelo Grupo de Estudos e Pesquisas: Paulo Freire e Educação Popular², em 2019.1, foi identificada a expressão "democracia" em dezenas de seus livros (PAULO, 2019, [S.I.]). Entre eles, Freire (1991), ao tratar da experiência de democratização do ensino, iniciada na gestão democrática da prefeita Luiza Erundina, diz que ela foi construída nos princípios da participação política. Freire (2014) alega a necessidade da participação popular no poder como caminho do processo de desalienação contra as sociedades fechadas e autoritárias.

Vale retomar o livro "Professora sim, tia não: cartas a quem ousa ensinar", no qual o educador afirmou que quando os professores e professoras faziam greve "estavam ensinando, estavam dando a seus alunos, pelo seu testemunho de luta, lições de democracia de que tanto precisamos neste país, acrescento eu agora." (FREIRE, 2015, p. 21). Verificamos em "Educação e mudança", a relação entre democracia e a luta contra todo tipo de autoritarismo (FREIRE, 2014). Além disso, o autor acentua que "estamos [...] no processo de aprender como fazer democracia” (FREIRE, 1991, p. 136).

Nesse sentido, a gestão democrática substantiva e radical é acompanhada por uma proposta de radicalizar a democracia, isto é, trata de um "processo radical de transformação do mundo" (FREIRE, 2011, p. 88). Guimarães e Freire (2013), ao dialogarem sobre suas experiências educativas, defendem uma democracia substantiva que requer uma concepção de ser humano enquanto gente, e não como máquina, a serviço do capitalismo. Fazem críticas às ditaduras e ao presidente Fernando Collor, insistindo que devemos brigar contra os governos nefastos. A prática educativa em prol de uma educação radicalmente democrática significa resistir às ideologias dominantes (FREIRE, 2013).

Portanto, nos estudos acerca da pedagogia freiriana, um dos elementos centrais para a busca pela superação da ideologia autoritária e antidemocrática é a participação popular dialógica. É interessante destacar que o diálogo em Paulo Freire (2013) é condição da libertação e da construção de um projeto de transformação social libertador. À vista disso, a dialogicidade é o caminho da participação que pressupõe ação e reflexão. Ou seja, não é uma pseudodemocracia ou pseudoparticipação, é uma prática de diálogo concreto que tem como princípio a participação democrática tanto individual como coletiva.

2 Coordenado por Fernanda dos Santos Paulo, inserido na Associação de Educadores Populares de Porto Alegre (AEPPA). 


\section{GESTÃO DEMOCRÁTICA COMO POLÍTICA EDUCACIONAL}

Nessa seção, discutiremos como a gestão educacional, para a escola pública, constitui-se como parte das políticas educacionais, principalmente após os anos 80 do século XX. Logo, começaremos enfatizando as medidas tomadas pelo poder público que as caracterizam (SAVIANI, 2008). Encontramos, por isso, no artigo 206 da Constituição Federativa do Brasil (BRASIL, 1988), a disposição de que a gestão democrática fará parte dos princípios que balizarão o ensino nos estabelecimentos escolares. Isso significa que, como propõe o preâmbulo da Carta Magna, nomeada como Constituição Cidadã, os "representantes do povo brasileiro, reunidos em Assembleia Nacional Constituinte para "instituir um Estado Democrático" (BRASIL, 1988, grifos nossos) reconheceram que a escola pública, para ser capaz de realizar suas funções e colaborar para a formação desse Estado, teria esse como um de seus fundamentos. A partir daí, a LDBEN (BRASIL, 1996) passou a discipliná-la, como ideia a ser implantada. Inicia, portanto, concebendo que:

Art. 14. Os sistemas de ensino definirão as normas da gestão democrática do ensino público na educação básica, de acordo com as suas peculiaridades e conforme os seguintes princípios: I - participação dos profissionais da educação na elaboração do projeto pedagógico da escola; II - participação das comunidades escolar e local em conselhos escolares ou equivalentes. (BRASIL, 1996, art. 14).

Fica assegurado, portanto, que professores deverão participar da construção do projeto da escola. Tal instrumento terá como finalidade, conceber os propósitos da instituição e a impulsionar para sua efetivação. Em outras palavras, cabe a esse projeto as compreensões política e pedagógica nas quais seus atores se inspiram e aspiram. Necessita, portanto, haver uma reflexão sobre a realidade política-econômica-social em que a escola se insere, e com qual educação - seu currículo, sua gestão, sua avaliação, seu clima escolar, etc. - estão comprometidos em desenvolver. Esses são alguns elementos para a construção de um documento que se realizará de forma participativa, dialógica e autônoma, que ajuíze a prática educacional pretendida. Assim, o projeto político-pedagógico (PPP), como tem sido denominado, "é uma forma da escola se pôr a avaliar sobre a realidade que tem, declarando suas necessidades, suas concepções, seus rumos e seus percursos para viabilizá-lo. Sendo, nesse sentido uma parte da organização escolar e seu planejamento." (COSTA, 2021, p. 221). 
O inciso do artigo 14 (BRASIL, 1996) se refere à participação da comunidade escolar, por meio de seus conselhos e afins, junto à direção do estabelecimento escolar. Isso porque, de acordo com o artigo 15, as escolas passariam a contar com autonomia pedagógica, administrativa e financeira, como atribuições a serem asseguradas, de forma gradativa, pelos respectivos sistemas educacionais.

Esses dois elementos que revelam e asseguram (na forma da lei) a importância da participação na construção da escola democrática, acontece porque historicamente tínhamos fazeres educacionais que confirmavam a realização de práticas autoritárias e centralizadoras. Vale lembrar que, até esse momento, as direções das escolas eram fortemente atreladas a um modelo mais técnicoburocrático (LÜCK, 2014) e "calcado nos pressupostos da Administração" (DRABACH; MOUSQUER, 2009), como jeito de gerir a escola pública. Isso equivale dizer que a estrutura educacional tinha um intenso arcabouço hierarquicamente verticalizado, marcado, na instituição escolar, pela centralidade da figura do diretor (PARO, 2015), o qual, além disso, desempenhava uma função destacadamente departamentalizada, preocupada com o formalismo, focada no cumprimento de normas e regulamentos e praticamente impessoal (LÜCK, 2014).

A ideia da gestão democrática vem, entretanto, disputar esse cenário. E, como nos lembra Arroyo (2011), é um bom sinal, porque revela a correlação de forças e nelas se identificam o papel dos profissionais da educação. Isso significa que eles podem diluir a institucionalização daquilo que parecia tão determinado e homogêneo. E, para isso, romper com a prática estabelecida por indivíduos que se percebiam precedidos do "poder", é luta pelo sonho político possível (FREIRE, 1995). Por isso, Lück (2014, p. 92-93) defenderá que é imprescindível combater “a prática individualizada e mais ainda a individualista e competitiva, empregada em nome e defesa de áreas e territórios específicos."

Nesse sentido, Freire (1995) justificará, como já abordamos, a importância da reforma administrativa que foi realizada quando secretário municipal de Educação de São Paulo, entre 1989 e 1991, que propôs um incremento nas "formas democráticas de agir" (p. 45). Isso significou, entre várias questões, a compreensão de que é preciso mudar a cara de nossa escola (FREIRE, 1991), o que não acontecerá de uma hora para outra. Essa transformação requer método, planejamento, propostas e atitudes que levam para tal possibilidade. Por isso, no sentido da democratização, Freire (1991) compreende que, antes de tudo, seja necessário haver clareza do projeto político de escola que se tem, para, então, enfrentar dialogicamente as estruturas, os embates e os instituídos. Para tanto, além de contar com estudos internos, realizados pela equipe da Secretaria de Educação, foram efetivados encontros com a comunidade escolar - pais, alunos, 
diretores, professores, coordenadores pedagógicos - para uma reflexão sobre a cara da escola e, principalmente, sobre seu currículo (FREIRE, 1991). "Assim, a gestão enfatiza a liderança na direção da finalidade, dando ênfase aos processos democráticos e participativos, situados no cotidiano da escola." (BORDIGNON; GRACINDO, 2000, p. 159).

A título de uma política pública, a democratização da administração educacional pode colaborar para o enfrentamento da tensão porque passa a gestão da educação, que, conforme propõe Barroso (2002, p. 173), pode ser sintetizada em três pilares: "crise de legitimidade do Estado; crise de governabilidade do sistema educativo; crise do modelo de educação pedagógica." Portanto, a equipe de Paulo Freire reconheceu e apontou um movimento importante para a construção de propostas democráticas junto às questões que envolviam a gestão do sistema educacional e da escola pública. O que mais tarde a própria LDBEN igualmente reconheceu (BRASIL, 1996).

A gestão democrática, como um elemento de políticas educacionais, trouxe a possibilidade de um rompimento importante para o cenário mais burocrático, centralizador, impositivo e autoritário, em que estava imerso o fazer educacional. Entretanto, sabemos que uma lei, por si só, não muda ambiente algum e que, por isso, é da valorização, muitas vezes ocorrida no interior da escola, que essa reflexão poderá ser efetivada e mudanças acontecidas. A política educacional, consequentemente, está para além das sanções legais, pois necessita, como afirma Freire (1991), de uma decisão frente às diversas defesas realizadas no plano do discurso. Para a democracia ser praticada, cabe diálogo, respeito, valorização, amorosidade e cidadania, rompendo com práticas autoritárias, verticalizadas e arrogantes. Em outras palavras, ele afirma que "a uma administração progressista, como nos incumbe fazer, essa burocracia perversa aniquila e emudece. E nós não vamos permitir que isso ocorra." (FREIRE, 1991, p. 34).

Concordamos, portanto, que a legislação educacional compreendeu a escola como ambiente para a construção de um país igualmente democrático e que a luta de Freire contribuiu para esse passo importante na realidade brasileira. Porém, como discutiremos mais adiante, a partir da meta 19 - Plano Nacional de Educação sobre uma gestão que caminhe nessa direção -, ainda há muito por fazer. 


\section{ENTRE A META 19 E A GESTÃO DEMOCRÁTICA: OLHARES A PARTIR DE POSSIBILIDADES FREIRIANAS}

Como já afirmamos, Paulo Freire, em sua gestão na Secretaria Municipal de Educação de São Paulo, defendeu e trabalhou na construção de uma escola pública popular e democrática, conhecida como "Escola Cidadã" e inspirada na Educação Popular (GADOTTI 1999, 2006). Isso significa: encarar as mazelas da sociedade brasileira, como já vimos, e desencadear uma gestão de políticas públicas que efetivamente contassem com a participação da comunidade escolar inteira. Essas experiências, de fato, contribuíram para muitas das administrações no campo dos governos populares e, para além delas, com lutas e fazeres comprometidos com a formulação e implementação de políticas educacionais progressistas.

Verificamos que no caso da proposta freiriana, a gestão democrática significa uma "transformação radical da máquina burocrática" (FREIRE, 1991, p. 34) e, para tanto, é necessário "nos engajarmos na luta por uma escola competente, democrática, séria e alegre” (FREIRE, 1991, p. 35). Por isso, a importância de um constante diálogo intra/escola e entre escola-comunidade-movimentos sociais na construção de seu desafio/sonho. Impossível mudar "a 'cara' da escola por portaria". [...] A Administração precisa testemunhar ao corpo docente que o respeita [...]. A Administração precisa deixar claro que pode errar. Só não pode é mentir." (FREIRE, 1991, p. 25).

O ideário de gestão democrática exige uma agenda de discussões, priorizando a participação popular, a valorização dos(as) trabalhadores(as) da educação e um currículo escolar contextualizado, para a superação das políticas que esmagam grande parte dos estudantes brasileiros e produzem a exclusão/ fracasso escolar, a desvalorização docente, as relações autoritárias, o verbalismo, enfim, tudo o que compõe a educação bancária.

Diante disso, reconhecemos na proposta de criação do Plano Decenal de Educação, existente na LDBEN (BRASIL, 1996), uma perspectiva de incrementar políticas educacionais que pudessem fortalecer a ideia de um progressivo avanço nas condições educacionais do país, para além de uma ou outra ação de governo. Afinal, uma marca das políticas educacionais brasileiras foi, ao longo da história, a intensa descontinuidade (SAVIANI, 2008) a que os governos as submeteram. Diferentemente do que ocorreu entre os governos dos presidentes Fernando Henrique Cardoso, Luiz Inácio Lula da Silva e Dilma Rousseff, no período de 1995 a 2016, quando muitas políticas foram ampliadas e reformuladas, mas com sinais de permanências e melhorias (FRANCO; BONAMINO, 2007; OLIVEIRA, 2009). A política educacional, como proposição do Estado/poder público acerca 
da educação (SAVIANI, 2008), guarda imensas contradições que fazem parte da realidade do país, principalmente no que diz respeito à possibilidade de equiparar o déficit frente às classes populares e àquele que apregoa cruelmente que tudo não passa de rankings, meritocracia, privatizações, etc.

No que se refere aos limites da política educacional brasileira, haveria muitos aspectos a considerar. Penso, porém, que as várias limitações são, em última instância, tributárias de duas características estruturais que atravessam a ação do Estado brasileiro no campo da educação desde as origens até os dias atuais. Refiro-me à histórica resistência que as elites dirigentes opõem à manutenção da educação pública; e à descontinuidade, também histórica, das medidas educacionais acionadas pelo Estado. A primeira limitação materializase na tradicional escassez dos recursos financeiros destinados à educação; a segunda corporifica-se na seqüência(sic) interminável de reformas, cada qual recomeçando da estaca zero e prometendo a solução definitiva dos problemas que se vão perpetuando indefinidamente. (SAVIANI, 2008, p. 07).

As duas estratégias reconhecidas pelo autor - escassez de financiamento e descontinuidade - são características de um pensamento político brasileiro que nega a construção da cidadania a tantos(as) brasileiros(as). As constantes opções da elite para negligenciar os direitos das classes populares é uma condição ainda maior quando existe a construção de políticas públicas progressistas. Por isso, a equipe de Freire, ao iniciar seu trabalho frente à Secretaria Municipal de Educação de São Paulo, tinha que considerar essa realidade.

É fundamental, creio, afirmar uma obviedade: os déficits referidos da educação entre nós castigam sobretudo as famílias populares. Entre os oito milhões de crianças sem escola no Brasil não há meninos ou meninas das famílias que comem, vestem e sonham. E mesmo quando, do ponto de vista da qualidade, a escola brasileira não atenda plenamente às crianças chamadas "bem-nascidas", são as crianças populares - as que conseguem chegar à escola e nela ficar - as que mais sofrem a desqualidade da educação. (FREIRE, 1991, p. 22).

Partir da ideia, portanto, de que na história da sociedade brasileira há uma contínua luta entre as iniquidades e as conquistas progressistas, é importante para nosso sonho em busca da construção de uma escola democrática. Sendo assim, também o PNE, sancionado em 9 de janeiro de 2001 (BRASIL, 2001) encontrou as amarguras do pensamento reacionário e antidemocrático que acomete a muitos no país. Vale lembrar que em seu artigo 87, parágrafo $1^{\circ}$ (BRASIL, 1996), fica disposto que "A União, no prazo de um ano a partir da publicação desta Lei, encaminhará, ao Congresso Nacional, o Plano Nacional de Educação, com diretrizes e metas para os dez anos seguintes, em sintonia com a Declaração Mundial sobre Educação para Todos.” Afirma, ainda, que será construído no 
âmbito de todos os entes federados e em colaboração. É evidente o caráter progressista de tal formulação, no sentido de enfrentar as mazelas constituídas e já expostas anteriormente. Contudo, novamente se evidenciam os grandes descompassos e uma dose de inércia, advindas da elite política brasileira, para que tal implementação seja freada e impossibilitada, visto que, por exemplo, o primeiro plano só se efetivou quatro anos após a promulgação da LDBEN, muito embora a sociedade civil já o tivesse realizado em 1997. Isso deflagra a necessária importância da organização social e dos governos progressistas para uma lei ser implementada, caso contrário, como já aludimos, torna-se "letra morta". É aqui que há uma possível contribuição dos gestores educacionais, sindicatos, lideranças que poderão defendê-la, promovê-la e se comprometerem com ela, ou, ao contrário, contribuir para seu impedimento e sua obstaculização.

Cabe destacar que no PNE 2001-2011 existia três considerações sobre a gestão democrática: uma afirmava a importância de compor a formação docente, e as outras duas atribuíam aos sistemas educacionais a normatização sobre ela, levando em conta a participação da comunidade. Já o PNE 2014-2024 traz 20 metas para a educação brasileira. A $19^{a}$ se refere à gestão democrática:

Meta 19 - assegurar condições, no prazo de dois anos, para a efetivação da gestão democrática da educação, associada a critérios técnicos de mérito e desempenho e à consulta pública à comunidade escolar, no âmbito das escolas públicas, prevendo recursos e apoio técnico da União para tanto. (BRASIL, 2014, p. 83).

E, a seguir, suas oito estratégias, onde podemos encontrar um tom gerencialista, performático e voltado para uma fiscalização por parte da comunidade (accountability), inclusive indicando transferências de recursos da União para os demais entes federados para aqueles que comprovarem mudanças nesse sentido (BRASIL, 2014). Ou na estratégia 19.8, quando propõe programas de formação de diretores e aplicação de prova nacional (BRASIL, 2014, p. 84), "na intenção subsidiar a definição de critérios objetivos para o provimento dos cargos."

De forma geral, há nas estratégias 19.4 e 19.5 (BRASIL, 2014) uma preocupação no sentido do fortalecimento dos conselhos escolares, dos sistemas (municipais e estaduais) e dos grêmios estudantis, contudo, é notório o caráter de uma participação na fiscalização da educação, o que deixa em descoberto o diálogo em torno das finalidades educativas propriamente ditas. Sobre isso, a estratégia 19.6 propõe: 
Estimular a participação e a consulta de profissionais da educação, alunos(as) e seus familiares na formulação dos projetos político-pedagógicos, currículos escolares, planos de gestão escolar e regimentos escolares, assegurando a participação dos pais na avaliação de docentes e gestores escolares. (BRASIL, 2014, p. 84, grifos nossos).

Observamos alguns dos princípios da escola cidadã, tais como a consulta pública à comunidade escolar, participação dos estudantes via grêmios estudantis e os conselhos municipais de educação, porém, há uma orientação, para a participação e à consulta de estudantes e pais, diferente daquela que propõe avaliar docentes e diretores - ficando a cargo tão somente dos pais. Nesse caso, parece tratar de uma gestão "democrática" que leva em consideração alguns atores inseridos no cotidiano escolar, negando o envolvimento de todos e todas que fazem parte dele. Isso, sem problematizar a inserção de funcionários, bem como daqueles que são responsáveis legais pelos estudantes. Diante disso, "mudar a cara" da educação, da política educacional e da gestão democrática é tarefa que ainda se faz presente. É por isso que a partir de Freire (1991), acreditamos que mudá-la, significa problematizá-la. Dialogar sobre ela com todos que a vivenciam.

\section{CONSIDERAÇÕES FINAIS}

A posição da pedagogia de Paulo Freire se ancora na necessidade de radicalizar a democracia, não a restringir. Diverge, por isso, das ideias mercadológicas e neoliberais presentes em governos que possuem como proposta reformas educacionais na perspectiva tecnicista-empresarial (mérito e desempenho). Segundo Freire (2000, p. 94): "Na visão pragmático-tecnicista contida em discursos reacionários, o que vale é a transferência de saberes técnicos, instrumentais, com que se assegure boa produtividade ao processo produtivo." $\mathrm{Na}$ mesma obra, o autor alerta para a educação a serviço do treinamento instrumental que visa resultados. A esse modelo educacional, Freire (1977) denominou de educação domesticadora. Também, no livro "Educação como prática da liberdade", ele atenta para a educação instrumental. Esse caráter de gestão aproxima-se com o projeto empresarial que pressupõe a "qualidade total", no lugar da qualidade social e da gestão democrática.

Os princípios mercadológicos de produtividade, individualidade e competitividade (AZEVEDO, 2007; GENTILI, 1994) norteiam a gestão empresarial sob o novo modelo tecnicista, conhecido como neotecnicismo. Essa educação está em oposição da gestão democrática freiriana. Na acepção da gestão empresarial, instrumento da hegemonia burguesa, os sujeitos da educação são clientes e, nesse sentido, a gestão necessita de instrumentos de eficiência e eficácia em prol de uma educação com qualidade total. Nesse viés, para Cabral Neto 
e Silva (2001, p. 15), “a escola passa a ser entendida como uma empresa e os professores, alunos e dirigentes transformam-se em trabalhadores que precisam se empenhar, ao máximo, para atingir a excelência proclamada."

Obviamente, ao analisar a meta 19 , e sua direção mais gerencialista, não estamos negando a contribuição do PNE, mas, ao contrário, propondo uma reflexão sobre esse tema específico, para que seja possível uma educação popular como possibilidade de aprofundamento de uma efetiva participação da comunidade escolar na construção da escola democrática.

\section{REFERÊNCIAS}

APPLE, Michael W. Para além da lógica do mercado: compreendendo e opondo-se ao neoliberalismo. Rio de Janeiro: Ache, 2005.

ARROYO, Miguel G. Currículo, território em disputa. 2. ed. Petrópolis: Vozes, 2011.

AZEVEDO, José Clóvis. Reconversão Cultural da Escola: Mercoescola e Escola Cidadã. Porto Alegre: Editora Sulina e Editora Universitária Metodista IPA, 2007.

BARROSO, João. Gestão local da educação: entre o Estado e o mercado, a responsabilização coletiva. In: MACHADO, Marcelino Lurdes; FERREIRA, Naura Syria Carapeto (org.). Política e Gestão da Educação: dois olhares. Rio de Janeiro: DP\&A, 2002. p. 173-197.

BORON, Atílio A. Estado, capitalismo e democracia na América Latina. 2. ed. Rio de Janeiro: Paz e Terra, 2002.

BORDIGNON, Genuino; GRACINDO, Regina Vinhaes. Gestão da educação: o município e a escola. In: FERREIRA, Naura Syria Carapeto; AGUIAR, Marcia Angela da S. (org.). Gestão da educação: impasses, perspectivas e compromissos. São Paulo: Cortez, 2000. p. 147-176.

BRASIL. Constituição da República Federativa do Brasil. Brasília: Senado Federal, 1988. 
BRASIL. Lei $\mathbf{n}^{\circ}$ 9394, de 20 de dezembro de 1996. Estabelece as diretrizes e bases da educação nacional. Disponível: http://www.planalto.gov.br/ccivil_03/ leis/19394.htm. Acesso em: 22 dez. 2020.

BRASIL. Lei $\mathbf{n}^{\circ}$ 10.172, de 9 de janeiro de 2001. Aprova o Plano Nacional de Educação e dá outras providências. Presidência da República. Casa Civil. Subchefia para Assuntos Jurídicos. Brasília, 9 de janeiro de 2001. Disponível em: http:/ /www. planalto.gov.br/ccivil_03/leis/leis_2001/110172.htm\#: :text $=$ Garantia $\% 20$ de $\% 20$ ensino $\% 20$ fundamental $\% 20$ obrigat $\%$ C $3 \%$ B 3 rio, e $\% 20$ a $\% 20$ conclus $\% \mathrm{C} 3 \% \mathrm{~A} 3 \mathrm{o} \% 20 \mathrm{desse} \% 20$ ensino. Acesso em: 17 jan. 2021.

BRASIL. Lei $\mathrm{n}^{\circ}$ 13.005, de 25 de junho de 2014. Aprova o Plano Nacional de Educação - PNE e dá outras providências. Plano Nacional de Educação 20142024. Câmara dos Deputados: Brasília 2014. (Série Legislação, n. 125). Disponível em: http://www.proec.ufpr.br/download/extensao/2016/creditacao/PNE\%20 2014-2024.pdf. Acesso em: 17 jan. 2021.

CABRAL NETO, Antônio e SILVA, Jorge Gregório. A construção histórica do paradigma da qualidade total no campo empresarial e a sua transplantação para o campo educacional. Revista Contexto e Educação. Editora Unijuí, ano 16, n. 12, p. 7-30, abr/jun, 2001.

COSTA, Daianny Madalena. Organização docente: contribuições da CNTE e da CTERA à escola pública e democrática. Curitiba: Appris, 2020.

COSTA, Daianny Madalena. O Projeto Político-Pedagógico - considerações acerca da gestão para a autonomia da escola. Reflexão e Ação, Santa Cruz do Sul, v. 29, n. 1, p. 218-232, jan. 2021. ISSN 1982-9949. Disponível em: https://online. unisc.br/seer/index.php/reflex/article/view/12513. Acesso em: 13 abr. 2021.

CURY, Carlos Roberto Jamil. Gestão democrática da educação: exigências e desafios. Revista Brasileira de Política e Administração da Educação, São Bernardo do Campo: v.18, nº 2, p.163-174, jul./dez. 2002.

DRABACH, Neila Pedrotti; MOUSQUER, Maria Elizabete Londero. Dos primeiros escritos sobre administração escolar no Brasil aos escritos sobre gestão escolar: mudanças e continuidades. Currículo sem Fronteiras, v. 9, n. 2, p. 258 285, jul/dez. 2009. 
FRANCO, Creso, ALVES, Fátima, BONAMINO, Alicia Qualidade do ensino fundamental: políticas, suas possibilidades, seus limites. Educ. Soc., out 2007, v. 28, n. 100, p. 989-1014.

FREIRE, Paulo. Simpósio "Educação para o Brasil”, organizado pelo Centro Regional de Pesquisas Educacionais do Recife, PE, em 1960. Publicada originalmente na RBEP v. 35, n. 82, p. 15-33, abr./ jun. 1961.

FREIRE, Paulo. Educação como prática da liberdade. Rio de Janeiro: Paz e Terra, 1967.

FREIRE, Paulo. Extensão ou comunicação? 3. ed. Rio de Janeiro: Paz e Terra, 1977.

FREIRE, Paulo. Paulo Freire: Educação é Prática da Liberdade: Reflexões de um educador cristão numa entrevista exclusiva a Tempo e Presença. Tempo e Presença, Rio de Janeiro, n. 154, p. 7, out. 1979a.

FREIRE, Paulo. Conscientização: teoria e prática da libertação: uma introdução ao pensamento de Paulo Freire. São Paulo: Cortez \& Moraes, 1979b.

FREIRE, Paulo. Paulo Freire com a palavra. Cadernos de Ensino Revista da União Est. de Estudantes RS, Porto Alegre, RS, n. 3, p. 4-18, ago. 1982.

FREIRE, Paulo. A educação na cidade. São Paulo: Cortez, 1991.

FREIRE, Paulo. À sombra desta mangueira. São Paulo: Olho d’Água, 1995.

FREIRE, Paulo. Pedagogia da indignação: cartas pedagógicas e outros escritos. São Paulo: UNESP, 2000.

FREIRE, Paulo. Política e Educação. 5. ed. São Paulo: Cortez, 2001.

FREIRE, Paulo. Educação \& Atualidade Brasileira. São Paulo, Editora Cortez, 2003.

FREIRE, Paulo. Pedagogia da autonomia: saberes necessários à prática educativa. São Paulo, Paz e Terra, 2011. 
FREIRE, Paulo. Pedagogia do oprimido. Rio de Janeiro: Paz e Terra, 2013. Disponível em: http://www.famep.com.br/repositorio/ebook/Pedagogia-doOprimido.pdf. Acesso em: 21 jan. 2021.

FREIRE, Paulo. Educação e mudança. 36. ed. São Paulo: Paz e Terra, 2014.

FREIRE, Paulo. Professora sim, tia não: cartas a quem ousa ensinar. 24. ed. rev. e atual. Rio de Janeiro: Paz e Terra, 2015.

FREIRE, Paulo; GUIMARÃES, Sérgio. Dialogando com a própria história [recurso eletrônico]. Rio de Janeiro: Paz e Terra, 2013.

FRIGOTTOO, Gaudêncio. Apresentação. In: FERREIRA, Márcia Ondina Vieira; GUGLIANO, Alfredo Alejandro. Fragmentos da globalização na educação: uma perspectiva comparada. Porto Alegre: Artes Médica Sul, 2000, p. 11-19.

GADOTTI, Moacir. (org.). Paulo Freire: uma biobibliografia. São Paulo: Cortez; Instituto Paulo Freire, 1996.

GADOTTI, Moacir. Caminhos e significados da educação popular em diferentes contextos. Cadernos de EJA, v . 6. São Paulo, IPF, 1999.

GADOTTI, Moacir. Escola Cidadã. 11. ed. Coleção Questões da Nossa Época, v. 24. São Paulo: Cortez, 2006.

GADOTTI, Moacir. Por que continuar lendo Pedagogia do oprimido? Revista de políticas públicas, v. 16, p. 459-461, 2012.

GENTILI, Pablo e SILVA, Tomás Tadeu (org.). Neoliberalismo, qualidade total e educação. Petrópolis: Vozes, 1994.

HARVEY, David. O neoliberalismo: histórias e implicações. 5. ed. São Paulo: Edições Loyola, 2014.

LAVAL, Christian. A escola não é uma empresa: o neo-liberalismo em ataque ao ensino público. Londrina: Editora Planta, 2004.

LÜCK, Heloísa. Gestão educacional: uma questão paradigmática. 11. ed. Petrópolis/RJ: Vozes. 2014. (Série cadernos de gestão). 
OLIVEIRA, Dalila Andrade. As políticas educacionais no governo Lula: rupturas e permanências. RBPAE, v. 25, n. 2, p. 197-209, mai./ago. 2009. Disponível em: http://seer.ufrgs.br/index.php/rbpae/article/view/19491. Acesso em: 10 dez. 2018.

PARO, Vitor Henrique. Diretor escolar: educador ou gerente? São Paulo: Cortez, 2015.

PAULO, Fernanda dos Santos. Caderno de Registros da Associação de Educadores Populares de Porto Alegre. Porto Alegre: [S.I.], 2019.

SANTOS, Milton. Por uma outra globalização: do pensamento único à consciência universal. Rio de Janeiro: Record. 200.

SAVIANI, Dermeval. Política educacional brasileira: limites e possibilidades. Revista de Educação PUC - Campinas, Campinas, v. 24, 2008, p. 07-16.

\footnotetext{
Daianny Madalena Costa

Doutora em Educação pela Universidade do Vale do Rio dos Sinos/Unisinos. Professora do Programa Pós-graduação em Gestão Educacional - Mestrado profissional, na Universidade do Vale do Rio dos Sinos - Porto Alegre. E-mail: daiannycosta@hotmail.com

\section{Fernanda dos Santos Paulo}

Doutora em Educação pela Universidade do Vale do Rio dos Sinos/Unisinos. Professora do Programa Pós-graduação em Educação da Universidade do Oeste de Santa Catarina (UNOESC). E-mail: fernanda.paulo@unoesc.edu.br
} 